\title{
ESI-MS Differential Fragmentation of Positional Isomers of Sulfated Oligosaccharides Derived from Carrageenans and Agarans
}

\author{
Alan G. Gonçalves, ${ }^{a}$ Diogo R. B. Ducatti, ${ }^{\mathrm{b}}$ T. Bruce Grindley, ${ }^{\mathrm{c}}$ \\ M. Eugênia R. Duarte, ${ }^{\text {b* }}$ and Miguel D. Noseda ${ }^{\mathrm{b} *}$ \\ a Departamento de Farmácia, Universidade Federal do Paraná, Paraná, Brazil \\ b Departamento de Bioquímica e Biologia Molecular, Universidade Federal do Paraná, Paraná, Brazil \\ ${ }^{c}$ Department of Chemistry, Dalhousie University, Halifax, Nova Scotia, Canada
}

\begin{abstract}
We have prepared a number of isomeric red seaweed galactan-derivative sulfated oligosaccharides to determine whether there were diagnostic differences among the isomeric mass spectra obtained using ESI CID MS/MS (triple quadrupole instrument). Fragmentation of the single or multicharged molecular ions from di-, tetra-, and hexasaccharides indicated that the relative positioning of the sulfate groups and type of monosaccharide unit affect the rate of cleavage of the glycosidic bonds. We also performed a comparative $[\mathrm{M}-\mathrm{Na}]^{-}$fragmentation study of positional isomers of sulfated disaccharides that present all four monosulfation possibilities on the galactopyranosidic ring. In this case, negative-ion ESI CID MS/MS approach gave diagnostic product ions from cross-ring cleavages along with the same main $B_{1}$ ion (from sulfated Galp), at $m / z 241$, for all isomers. The isomeric disaccharides were also submitted to increased spray energy conditions inducing in-source fragmentation; preformed $B_{1}$ ions were then fragmented to give similar product ions as those found in $[\mathrm{M}-\mathrm{Na}]^{-}$analysis. Evaluation of the relative abundances mainly for cross-ring fragment ions at $m / z 138,139,151$, 153 allowed clear distinction among the members of the disaccharide series. The different ratios for $\mathrm{m} / \mathrm{z} 151 / 153$ ions were consistent with the predominance of $\mathrm{m} / \mathrm{z} 153$ being related to the cases when the bond involved in the cleavage process links a sulfated carbon. A quadrupole ion trap instrument ( $\mathrm{MS}^{n}$ analysis) was also utilized to compare the results obtained with the triple quadrupole instrument. (J Am Soc Mass Spectrom 2010, 21, 1404-1416) @ 2010 American Society for Mass Spectrometry
\end{abstract}

S ulfated saccharides are involved in a wide range of biological processes such as neuronal development [1], tumor growth and metastasis [2, 3], inflammation, viral invasion, nerve tissue growth, and plaque formation $[4,5]$. It is now recognized that the regiochemistry and stereochemistry of the positions of the sulfates are highly significant for their recognition, the "sulfation code" [6, 7]. Thus, the development of diverse tools for the structural determination of sulfated sugars has become extremely important. In this context, a high number of publications have been focused on the study of sulfated sugar-containing macromolecules through the mass spectrometric analysis of their enzymatically or chemically produced oligosaccharides [8-12]. The earlier studies $[13,14]$ in this field were mostly conducted using FAB ionization. More recently, a number of combinations of ionization techniques (MALDI [15-17] and ESI [18-22] and mass analyzers (TOF [15-17, 22] quadrupoles and/or ion traps [8-12, 18-22] have been utilized. Sul-

Address reprint requests to Dr. M. D. Noseda, Departamento de Bioquímica e Biologia Molecular, Universidade Federal do Paraná, P.O. Box 19046, Curitiba, Paraná, Brazil. E-mail: mdn@ufpr.br

* Research member of the National Research Council of Brazil (CNPq). fated oligosaccharides produced from glycosaminoglycans (hyaluronan sulfate, chondroitin sulfate [11, 12], heparan sulfate [22], heparin [13, 14, 19-23], dermatan sulfate [16], mucin [8, 9], and mucopolysaccharides [24] have served as models for the improvement of the knowledge of mass spectrometric methods involving these types of molecules.

Many of the aforementioned studies have been dedicated to determine the sulfation position of isomeric oligosaccharides. Evaluation of the losses of monosaccharide units by sequencing mass spectrometry is normally sufficient to determine the sulfation pattern of isomers bearing sulfate groups on different monosaccharide units [10,17]. In cases where the differences are only related to the position occupied by the sulfate groups in the same monosaccharide ring, the determination of the positional isomer is more difficult. Most of the studies carried out with this aim have been performed to determine the location and degree of sulfation for 4- and/or 6-sulfated HexNAc of chondroitin sulfate-oligosaccharides. For this purpose, control of the charge state of the parent ion followed by determination of the relative abundance of the product ions generated from the cleavage of the glycosidic linkage 
has been employed [25-27]. The use of collision induced dissociation (CID) leading to cross-ring fragmentation has also been utilized to correlate unique product ions to sulfate group positioning in the sugar ring. This approach has been performed to differentiate 2-O-, 3-O-, and 4-O- $\mathrm{SO}_{3}$ L-fucose monosaccharides [28]. 4-Oand 6-O-SO $\mathrm{S}_{3}$ GalNAc units in chondroitin oligosaccharides [29]. 6-O- and 2- $\mathrm{N}$-heparin sulfated disaccharides [19], and sulfo-Lewis a (3-O- $\mathrm{SO}_{3}$ Galp-containing oligosaccharide) and 6-O- $\mathrm{SO}_{3}$ galactose [9]. More recently [23], the differentiation of $3-\mathrm{O}-\mathrm{SO}_{3}$ and $6-\mathrm{O}-\mathrm{SO}_{3}$ in glucosamine residues of heparin disaccharides was accomplished through cross-ring dissociation using $\mathrm{MS}^{3}$ product ion spectra. Liu and coworkers [30] also demonstrated ESI-MS/MS differential cross-ring cleavage patterns of various synthetic isomers of disulfated glucosamine glycosides.

Red seaweed galactans are also among the industrially and biologically relevant classes of sulfated polysaccharides that have been studied through mass spectrometry [15, 17, 31-37]. These polysaccharides are primarily classified as agarans and carrageenans. Both types of galactans are essentially constituted of the disaccharide-based repeating unit of $(1 \rightarrow 3)-\beta$-D-Gal $p-(1 \rightarrow$ 4) $-\alpha$-Gal $p$, and in many cases, the latter residues appears as 3,6-AnGalp. The difference between the two types of galactans lies in the enantiomeric configuration of the $\alpha$-units, which are L- in agarans and D- in carrageenans [38]. They are usually found as anionic polymers with varying degrees of sulfation, presenting a wide variety of substitution patterns. The rheological aspects of the gelling or thickening properties presented by several of these polysaccharides, which are useful in food industry, have been related to the sulfate content and positioning $[39,40]$. Moreover, the cyclization reactions of agarans and carrageenans, which are utilized in industry to enhance gelation properties of these polymers, are also influenced by the sulfation positioning [41-45]. More importantly, highly sulfated red seaweed galactans have shown antiviral properties against enveloped virus, such as HSV [46-50] and dengue virus [51-53]. The antiviral activity is directly affected by the position occupied by the sulfate groups. Recent evidence indicates that this kind of sulfated polymer might become increasingly important in drug development for the prevention of sexually transmitted diseases soon [54]. The determination of the sulfation positioning of algal sulfated polysaccharides (which is commonly conducted by use of NMR spectroscopy) is then essential to correlate sulfation patterns with physico-chemical and biological properties.

Published data focused on mass spectrometric analysis of oligosaccharides produced from sulfated red seaweed galactans are less diverse than those described for glycosaminoglycans. Most of these studies are restricted to carrageenans (often $\kappa$-carrageenan) [15, 32, $33,35]$. Few examples of mass spectrometric studies of isomeric carrageenan-oligosaccharides comparing different sulfation patterns have been described $[10,17$,
32]. Although there are red seaweeds that biosynthesize carrageenan and/or agarans containing sulfate groups located at C-2, C-4, or C- 6 in the $\beta$-D-Gal $p$ unit (not at $\mathrm{C}-3$, because this position is involved in the glycosidic linkage), there are no published data that allow the differentiation of their isomeric sulfated oligosaccharides by using mass spectrometry.

For this purpose, we have prepared sulfated oligosaccharide alditols through partial reductive hydrolysis of polysaccharides extracted from four selected red seaweed species. Each species produces sulfated galactans presenting one kind of sulfation pattern. By using this strategy, we have obtained sulfated 3,6-anhydrogalactosecontaining oligosaccharides $\left(2-\mathrm{O}-\mathrm{SO}_{3}\right.$-di-and tetrasaccharide alditols) and a number of sulfated galactose-containing oligosaccharides (4-O- $\mathrm{SO}_{3}$-di-, tetra-, and hexasaccharide alditols, $6-\mathrm{O}-\mathrm{SO}_{3}$-disaccharide alditol, and $2-\mathrm{O}-\mathrm{SO}_{3}-$ disaccharide alditol) [34]. To complete the series of the four possible isomeric monosulfated galactopyranosecontaining disaccharides, we developed a semi-synthetic route to prepare a $3-\mathrm{O}-\mathrm{SO}_{3}$-disaccharide alditol from commercial agarose [55]. Here we describe a mass spectrometric study dedicated to uncovering differences in the spectra of positional isomers of sulfated oligosaccharides obtained from red seaweed galactans that can be used for analytical purposes. The use of negative-ion ESI CID MS/MS spectra provided glycosidic bond cleavages that were distinct for the tetrasaccharide sulfated isomers. It was also possible to differentiate the four sulfated galactose isomeric disaccharides by simple CID MS/MS fragmentation of the $[\mathrm{M}-\mathrm{Na}]^{-}$ion. These results were confirmed by setting spectrometer source parameters to allow the spray source energy to be increased to an extent that was sufficient to induce the cleavage of glycosidic bonds through $\mathrm{B}_{1}$ fragmentation (fragment nomenclature as described by Domon and Costello [56]. The produced sulfated $B_{1}$ ion was then submitted to CID, leading to spectra containing unique combinations of cross-ring ions for each isomer, which were complementary to those fragments observed in the $[\mathrm{M}-\mathrm{Na}]^{-}$ CID fragmentation. Discussions of fragment ion relative abundances, possible cleavage mechanisms, and the differences found between CID MS/MS and MS ${ }^{n}$ results are presented.

\section{Experimental}

\section{Materials and Polysaccharides}

Solutions for mass spectrometry experiments were prepared with acetonitrile HPLC grade and ultrapurified water. Borane 4-methylmorpholine complex (4-MMB) utilized in the hydrolytic processes was purchased from Sigma-Aldrich (St. Louis, MI, USA).

Naturally sulfated polysaccharides were extracted from the appropriated red seaweeds and then processed through well established procedures, as previously described [34]. Samples of Kappaphycus alvarezii 
(Gigartinales) were obtained in the laboratory and cultivated in the sea (Ubatuba, São Paulo, Brazil). Aqueous extraction of the processed algal material generated $\kappa$-carrageenan $\left[(1 \rightarrow 3)-\beta\right.$-D-Gal $p-4-\mathrm{OSO}_{3}-(1 \rightarrow 4)-\alpha$ D-3,6-An-Galp]. Gigartina skottsbergii (Gigartinales) samples were collected in Bahia Camarones (Chubut Province, Argentina); in this case, the aqueous soluble polysaccharide corresponds to $\lambda$-carrageenan, which was submitted to alkaline treatment rendering $\theta$-carrageenan $[(1 \rightarrow 3)-\beta$ D-Galp-2-OSO ${ }_{3}-(1 \rightarrow 4)-\alpha$-D-3,6-An-Galp-2-OSO 3 ] [57]. Specimens of Acanthophora spicifera (Ceramiales) were collected in Bombinhas-Santa Catarina State, Brazil. Aqueous extraction followed by alkaline treatment yielded pyruvylated agarose 2 -sulfate $[(1 \rightarrow 3)-\beta$-D-Galp-2-OSO$-(1 \rightarrow$ 4)- $\alpha$-L-3,6-An-Gal $p$ ] [48]. Agarose-6-sulfate [ $(1 \rightarrow 3)-\beta$-DGal $p-6-\mathrm{OSO}_{3}-(1 \rightarrow 4)-\alpha$-L-3,6-An-Gal $p$ ] was extracted from cultivated samples of Gracilaria domingensis (Gracilariales) $[34,58]$. Commercial agarose $[(1 \rightarrow 3)-\beta-\mathrm{D}-\mathrm{Gal} p-(1 \rightarrow$ 4)- $\alpha$-L-3,6-An-Galp] Type 1 (Sigma-Aldrich) was utilized as starting material for the semi-synthesis of the 3-Osulfated oligosaccharide alditol, as previously [55].

\section{Sulfated Oligosaccharide Alditols}

Oligosaccharides were prepared through partial reductive hydrolysis from each of the red seaweed galactans utilized here: polysaccharide $(1 \mathrm{~g} \%)$ was incubated with TFA $(0.5 \mathrm{M})$ in the presence of 4 -MMB $(\sim 0.6 \mathrm{M})$ for $8 \mathrm{~h}$ at $65^{\circ} \mathrm{C}$ [59]. Hydrolysis product purification was performed by anion exchange chromatography (DEAESephadex $\mathrm{A} 25, \mathrm{Cl}^{-}$form) with a $\mathrm{NaCl}$ gradient. The resulting fractions were then desalted by use of gelfiltration chromatography on a water-eluted Bio-Gel P2 column $[31,34]$. From $\theta$-carrageenan, di- and tetrasaccharide alditols $\beta$-D-Galp- $(1 \rightarrow 4)-3,6-A n-D-G a l O H$ $2-\mathrm{OSO}_{3}$ (carrabiitol $2^{1}$-sulfate, G-AOH2S, 1) and $\beta$-DGalp-(1 $\rightarrow$ 4)-3,6-An- $\alpha$-D-Galp $2-\mathrm{OSO}_{3}-(1 \rightarrow 3)-\beta-\mathrm{D}-$ Galp-(1 $\rightarrow$ 4)-3,6-An-D-GalOH 2-OSO 3 (carratetraitol $2^{1}, 2^{3}$-disulfate, G-A2S-G-AOH2S, 2) were prepared [34]. $\kappa$-Carrageenan yielded di-, tetra-, and hexasaccharide alditols $\beta$-D-Galp-4-OSO 3 - $(1 \rightarrow 4)-3,6-A n-D-G a l O H ~(c a r-$ rabiitol $4{ }^{2}$-sulfate, G4S-AOH, 3), $\beta$-D-Galp-4-OSO $-(1 \rightarrow$ 4)-3,6-An- $\alpha$-D-Gal $p-(1 \rightarrow 3)-\beta$-D-Galp-2-OSO $-(1 \rightarrow 4)-3,6-$ An-D-GalOH (carratetraitol $4^{2}, 4^{4}$-disulfate, G4S-A-G4SAOH, 4) and $\beta$-D-Galp-4-OSO $-(1 \rightarrow 4)-3,6-A n-\alpha$-D-Gal $p-(1$ $\rightarrow 3)-\beta$-D-Gal $p-4-\mathrm{OSO}_{3}-(1 \rightarrow 4)-3,6-\mathrm{An}-\alpha$-D-Gal $p-(1 \rightarrow 3)-\beta-$ D-Galp-2-OSO $-(1 \rightarrow 4)-3,6-\mathrm{An}-\mathrm{D}-\mathrm{GalOH}$ (carrahexaitol $4^{2}, 4^{4}, 4^{6}$-trisulfate, G4S-A-G4S-A-G4S-AOH, 5) [34]. Pyruvylated agarose 2-sulfate rendered disaccharide $\beta$-D-Gal $p$-2$\mathrm{OSO}_{3}-(1 \rightarrow 4)-3,6-\mathrm{An}-\mathrm{L}-\mathrm{GalOH}$ (agarobiitol $2^{2}$-sulfate, G2SAOH, 6) [31, 34]. From agarose 6-sulfate, disaccharide $\beta$-DGalp-6-OSO ${ }_{3}-(1 \rightarrow 4)-3,6-\mathrm{An}-\mathrm{L}-\mathrm{GalOH}$ (agarobiitol 6 -sulfate, G6S-AOH, 7) was prepared [34].

$\beta$-D-Galp-3-OSO ${ }_{3}-(1 \rightarrow 4)-3,6-\mathrm{An}-\mathrm{L}-\mathrm{GalOH}$ (agarobiitol $3^{2}$-sulfate, G3S-AOH, 8) was semi-synthetically prepared as follows: purification of neutral disaccharide alditol from agarose partial reductive hydrolyzate (flash chromatography), protection of the primary hydroxyls with trityl groups, regioselective dibutylstannylenemediated 3-O-sulfation of the galactopyranosidic ring followed by detritylation to give the desired product [55].

\section{Electrospray Triple Quadrupole Mass Spectrometry}

Negative-ion mode ESI-CID MS/MS experiments were conducted with an API 3200 instrument (Applied Biosystem/MDS SCIEX, Concord, ON, Canada). For all analysis, samples were diluted $(5-10 \mathrm{ng} / \mu \mathrm{L})$ in acetonitrile/water (7:3) and introduced into the spectrometer source through direct infusion with a syringe pump at a flow rate of $10 \mu \mathrm{L} / \mathrm{min}$. Data acquisition and processing were conducted using Analyst software (MDS SCIEX, Concord, ON, Canada). Ionization was provided by a Turbo-IonSpray probe with the source operating at $100{ }^{\circ} \mathrm{C}$. Nitrogen was used as the auxiliary, curtain and collision gas. Each spectrum was recorded for $2 \mathrm{~min}$, which corresponded to a combined 40 scans. A propylene glycol standard mixture (PPG Standard, PE SCIEX) was utilized for instrument calibration. Full scan single MS and molecular ions CID MS/MS analyses were run with the ionization source (IS), declustering potential (DP) and entrance potential (EP) at -4.0 $\mathrm{kV},-20 \mathrm{~V}$, and $-10 \mathrm{~V}$, respectively; collision energies (from -40 up to $-70 \mathrm{eV}$ ) were as indicated in Figures and Tables presented here. For $\mathrm{B}_{1}$ CID MS/MS experiments, the parameters were $-4.5 \mathrm{kV}$ (IS), $-100 \mathrm{~V}$ (DP), and keeping $-10 \mathrm{~V}(\mathrm{EP})$; collision energy was adjusted at $-30 \mathrm{eV}$.

\section{Electrospray Quadrupole Ion Trap Mass Spectrometry}

$\mathrm{MS}^{n}$ experiments were performed with a ThermoFinnigan LCQ spectrometer (San Jose, CA, USA). Xcalibur 1.0 software was used for data acquisition and processing. A standard mixture of fluorinated phosphazines (Ultramark 1621; Sigma-Aldrich) was utilized for instrument calibration. Samples $(5-10 \mathrm{ng} / \mu \mathrm{L})$, in acetonitrile/water (7:3), were introduced into spectrometer by a syringe pump (10 $\mu \mathrm{L} / \mathrm{min})$. For full-scan $\mathrm{MS}^{1}$ or $\mathrm{MS}^{n}$ experiments, spectra were recorded in negative-ion mode with capillary temperature of $200{ }^{\circ} \mathrm{C}$. Argon was utilized as collision gas. Spray (SV) and capillary voltages (CV) as well as normalized collision energies (NCE) were adjusted to provide better responses for each series of isomers studied: for disaccharides -4.5 $\mathrm{kV}(\mathrm{SV}),-22 \mathrm{~V}(\mathrm{CV})$, and 25\% (NCE); for tetrasaccharides $-4.5 \mathrm{kV}(\mathrm{SV}),-10 \mathrm{~V}(\mathrm{CV})$, and $29 \%(\mathrm{NCE})$; for hexasaccharide $-3.7 \mathrm{kV}(\mathrm{SV}),-10 \mathrm{~V}(\mathrm{CV})$, and $26 \%$ (NCE). Optimization of the signal from the precursor ion of interest was performed using the automatic tune feature on the instrument. Each mass spectrum was an average of 10 scans. 


\section{Results and Discussion}

Agarans and carrageenans extracted from some selected red seaweed species present repetitive sulfation patterns and, therefore, can be attractive sources of oligosaccharides with specific sulfation positioning. These kind of oligosaccharides have been used in diverse areas, such as the preparation of potential antiviral agents [55, 60], model molecules in NMR spectroscopy/mass spectrometry studies [31, 34, 59, 61-63], and as standards in capillary electrophoresis separations [34]. Partial acidic hydrolysis is an efficient way to obtain sulfated oligosaccharides from those galactans that contain 3,6-anhydrogalactopyranosyl residues, mainly because the glycosidic bonds of the 3,6-anhydrogalactopyranosyl units are significantly more acid-labile than those of most pyranosides. When the hydrolytic process is conducted in the presence of 4-MMB (an acid stable reducing agent), oligosaccharides having an even number of monosaccharide units with 3,6-AnGalOH residues as terminal units are produced (oligosaccharide alditols). For this work, carrabiitol $4^{2}$-sulfate (G4S-AOH, 3), carratetraitol $4^{2}, 4^{4}$-disulfate (G4SA-G4S-AOH, 4) and carrahexaitol $4^{2}, 4^{4}, 4^{6}$-trisulfate (G4S-A-G4S-A-G4S-AOH, 5) were readily prepared via partial reductive hydrolysis of Kappaphycus alvarezii carrageenan [34]. This was possible because this seaweed produces mainly $\kappa$-carrageenan, a highly repetitive galactan containing $(1 \rightarrow 3)-\beta$-D-Galp-4-OSO3- $(1 \rightarrow$ 4)- $\alpha$-D-3,6-An-Galp as the repeating unit sequence. The oligosaccharides produced from $\theta$-carrageenan were completely desulfated at C-2 of the $\beta$-D-Galp units but retained the sulfate groups at the same position of the $\alpha$-units. The selective cleavage of part of the sulfate groups during $\theta$-carrageenan hydrolysis provided us with a monosulfated disaccharide (G-AOH2S, 1) and a disulfated tetrasaccharide (G-A2S-G-AOH2S, 2), which form two positional isomer pairs with the $\kappa$-carrageenan derivative di- (G4S-AOH, 3) and tetrasaccharides (G4S-A-G4S-AOH, 4). Also, by hydrolyzing appropriated sulfated agarans (pyruvylated agarose 2-sulfate and agarose 6-sulfate) we prepared G2S-AOH (6) and G6S-AOH (7). To overcome the impossibility of obtaining a naturally sulfated oligosaccharide containing a 3-O-sulfated- $\beta$-D-Gal $p$ unit (because of the glycosidic linkage in this kind of polysaccharide) we also semi-synthetically produced disaccharide $\beta$-D-Gal $p$-3$\mathrm{OSO}_{3}-(1 \rightarrow 4)-3,6-\mathrm{An}-\mathrm{L}-\mathrm{GalOH}(\mathrm{G} 3 \mathrm{~S}-\mathrm{AOH}, 8)$ [55]. This strategy allowed us to prepare a series of four disaccharides that incorporated all possible monosulfate substitutions on the galactopyranose ring. The preparation routes for all oligosaccharide alditols utilized in this work are outlined in Scheme S1, of the Supplemental Information, which can be found in the electronic version of this article.

All mass spectrometry experiments were run in the negative-ion mode, taking advantage of the presence of the negatively charged sulfate groups on the oligosaccharide structures. We also could observe $[\mathrm{M}+\mathrm{Na}]^{+}$ ions by using the positive-ion mode, which gave analyzable spectra (data not shown). However, negativeion mode ESI-MS is widely recognized as the standard analytical method for the analysis of sulfated oligosaccharides, giving rise to higher sensitivity than positiveion mode. Also, the sulfated fragment ions could be identified directly without considering adduct mass subtractions. All sulfated oligosaccharide alditols studied here were obtained and kept as sodium salts for mass spectrometric analyses. Samples were analyzed on both the triple quadrupole (CID MS/MS) and quadrupole ion trap $\left(\mathrm{MS}^{n}\right)$ instruments for comparison of the results; however this work is focused on the CID MS/MS analysis.

\section{Product Ion Mass Spectra of Sulfated Hexa- and Tetrasaccharide Alditols}

The ESI-MS spectrum of trisulfated hexasaccharide G4S-A-G4S-A-G4S-AOH (5) presented singly [M-Na] ${ }^{-}$ $(\mathrm{m} / \mathrm{z} 1221)$, doubly $[\mathrm{M}-2 \mathrm{Na}]^{2-}(\mathrm{m} / \mathrm{z} 599)$ and triply charged $[\mathrm{M}-3 \mathrm{Na}]^{3-}(\mathrm{m} / \mathrm{z}$ 392) molecular ions (Figure S1). The singly charged $\left(\mathrm{m} / \mathrm{z} 1221\right.$ [M-Na] $\left.^{-}\right)$molecular ion was found in a very low relative abundance $(\sim 0.1 \%)$. Consequently, it was not possible to produce an analyzable CID MS/MS spectrum from $[\mathrm{M}-\mathrm{Na}]^{-}$. CID MS/MS from the more abundant $m / z 599[\mathrm{M}-2 \mathrm{Na}]^{2-}$ and $\mathrm{m} / \mathrm{z} 392[\mathrm{M}-3 \mathrm{Na}]^{3-}$ ions generated several glycosidic fragments (Figure 1a and b, respectively), presenting triply, doubly and singly charged product ions. The main product ions from glycosidic cleavage observed for G4S-A-G4S-A-G4S-AOH (5) analysis corresponded to losses of disaccharide moieties, where both of the fragmented glycosidic linkages are the ones closer to the sulfate groups. Glycosidic fragments $\mathrm{Y}_{3}, \mathrm{C}_{3}$, and $\mathrm{B}_{3}$ ions were considerably less intense than the $B_{2}, C_{2}$, and $\mathrm{Y}_{2}$ or $\mathrm{B}_{4}, \mathrm{C}_{4}$, and $\mathrm{Y}_{4}$ ions. The product ion assigned as $\mathrm{B}_{1}$ was the only evident glycosidic fragment which originated from a glycosidic bond cleavage that was not close to any sulfate group. MS $^{2}$ analysis of G4S-A-G4SA-G4S-AOH (5) gave similar results as those found in the ESI CID MS/MS analysis. The only significant difference was the product ion spectrum from the singly charged molecular ion, which could be generated by using this technique (Figure S2); although no further glycosidic cleavages were observed in this case.

As expected, single quadrupole full scan spectra of ESI-MS of the isomeric disulfated tetrasaccharides G4SA-G4S-AOH (4) and G-A2S-G-AOH2S (2) gave the same molecular ions [M-Na] ${ }^{-}$and $[\mathrm{M}-2 \mathrm{Na}]^{2-}$ at $\mathrm{m} / \mathrm{z} 813$ and 395, respectively (Figure S3). CID MS/MS of G4SA-G4S-AOH (4) [M-Na $]^{-}$presented two main product ions at $m / z 405\left(\mathrm{Y}_{2}\right)$ and $385\left(\mathrm{~B}_{2}\right)$ with $100 \%$ and $63.2 \%$ of relative abundances, respectively (Table 1). As shown in Figure 2a and c, these glycosidic fragment ions resulted from the central glycosidic bond cleavage of G4S-AG4S-AOH (4). Nevertheless, for G-A2S-G-AOH2S (2) $\mathrm{m} / \mathrm{z} 405\left(\mathrm{Y}_{2}\right)$ and $385\left(\mathrm{~B}_{2}\right)$ relative abundances corre- 

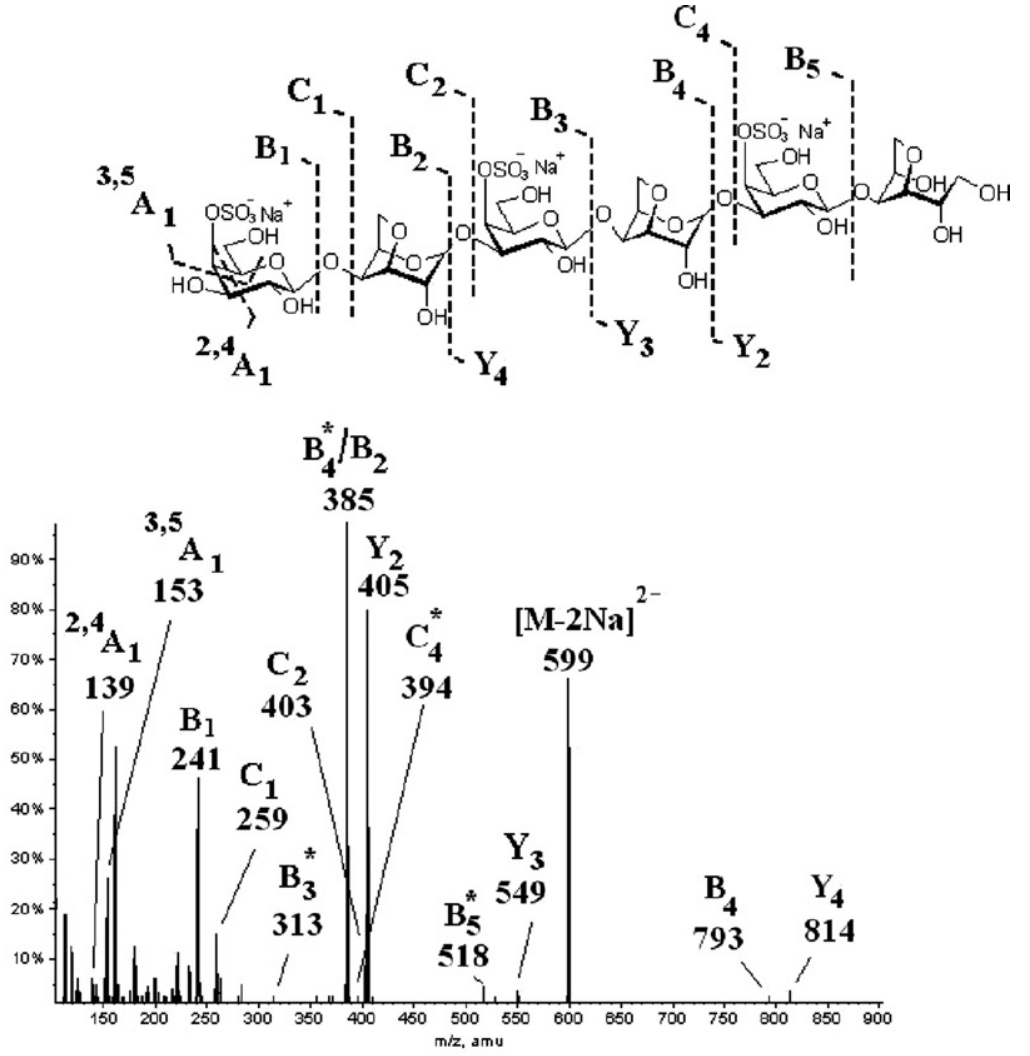

(a)
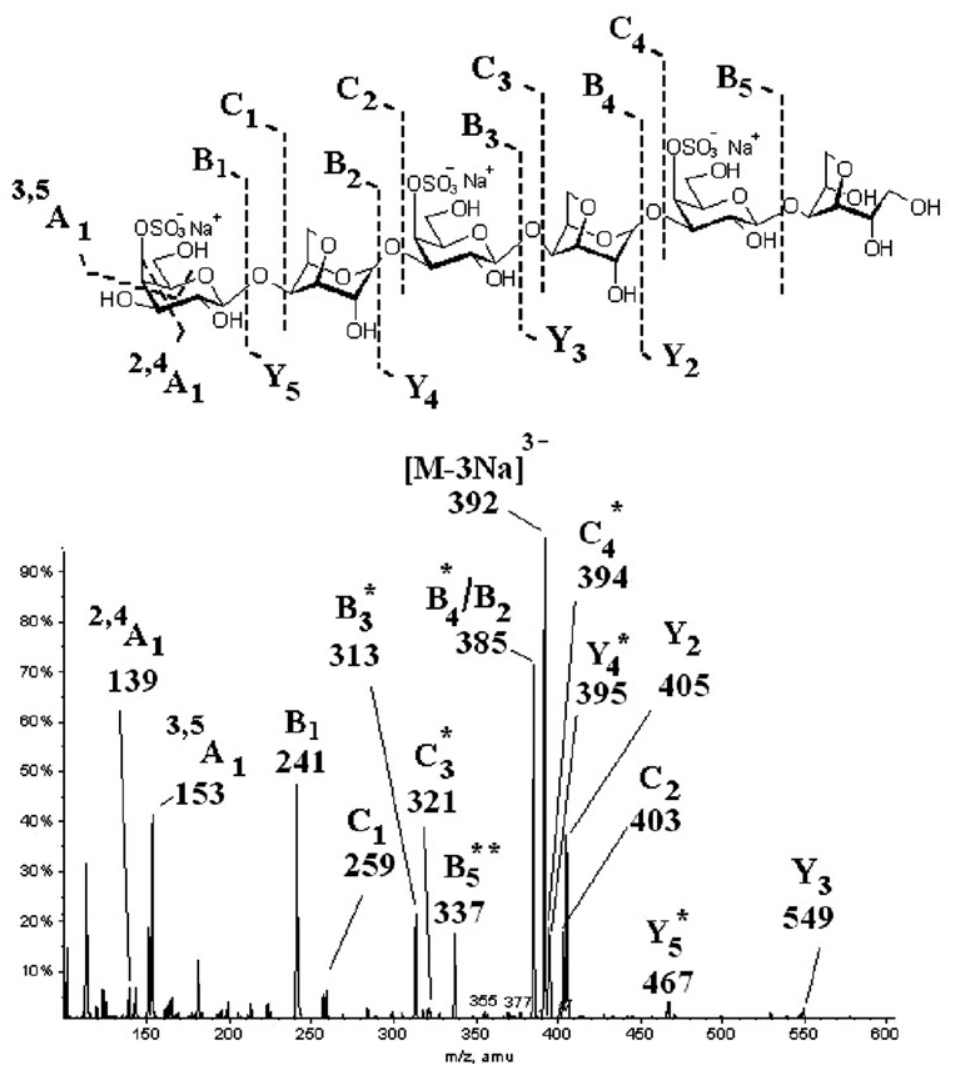

(b)

Figure 1. ESI CID MS/MS spectra of G4S-A-G4S-A-G4S-AOH (5) $[\mathrm{M}-2 \mathrm{Na}]^{2-}(\mathbf{a})$ and $[\mathrm{M}-3 \mathrm{Na}]^{3-}(\mathbf{b})$; collision energy was set at -55 and $-40 \mathrm{eV}$, respectively. Doubly charged and triply charged product ions are highlighted with $\left(^{*}\right)$ and $(* *)$, respectively. 
Table 1. Fragment ions and relative abundances observed for G4S-A-G4S-AOH and G-A2S-G-AOH2S in CID MS/MS analysis with $m / z 813$ [M-Na] $]^{-}$and $m / z 395$ [M-2Na $]^{2-}$ as precursor ions

\begin{tabular}{|c|c|c|c|c|c|c|c|c|c|c|c|c|}
\hline \multirow{4}{*}{$\begin{array}{l}\text { Fragment } \\
\text { ion }(\mathrm{m} / \mathrm{z})\end{array}$} & \multicolumn{6}{|c|}{$\mathrm{MS}^{2}$} & \multicolumn{6}{|c|}{ CID MS/MS } \\
\hline & \multicolumn{3}{|c|}{ G4S-A-G4S-AOH (4) } & \multicolumn{3}{|c|}{ G-A2S-G-AOH2S (2) } & \multicolumn{3}{|c|}{ G4S-A-G4S-AOH (4) } & \multicolumn{3}{|c|}{ G-A2S-G-AOH2S (2) } \\
\hline & \multirow{2}{*}{$\begin{array}{c}\text { Fragment ion } \\
\text { type }\end{array}$} & \multicolumn{2}{|c|}{$\begin{array}{c}\text { Relative } \\
\text { abundances of } \\
\text { fragments from }\end{array}$} & \multirow{2}{*}{$\begin{array}{c}\text { Fragment ion } \\
\text { type }\end{array}$} & \multicolumn{2}{|c|}{$\begin{array}{c}\text { Relative } \\
\text { abundances of } \\
\text { fragments from }\end{array}$} & \multirow{2}{*}{$\begin{array}{c}\text { Fragment } \\
\text { ion type }\end{array}$} & \multicolumn{2}{|c|}{$\begin{array}{c}\text { Relative } \\
\text { abundances of } \\
\text { fragments from }\end{array}$} & \multirow{2}{*}{$\begin{array}{c}\text { Fragment ion } \\
\text { type }\end{array}$} & \multicolumn{2}{|c|}{$\begin{array}{c}\text { Relative } \\
\text { abundances of } \\
\text { fragments from }\end{array}$} \\
\hline & & $m / z 813$ & $m / z 395$ & & $\mathrm{~m} / \mathrm{z} 813$ & $m / z 395$ & & $m / z 813$ & $m / z 395$ & & $m / z 813$ & $m / z 395$ \\
\hline 139 & - & - & - & - & - & - & ${ }^{2,4} \mathrm{~A}_{1}$ & $3.9 \%$ & $3.7 \%$ & - & - & - \\
\hline 153 & - & - & - & - & - & - & ${ }^{3,5} \mathrm{~A}_{1}$ & $4.5 \%$ & $16.4 \%$ & - & - & - \\
\hline 225 & - & - & - & $\mathrm{Z}_{1}$ & - & $2.3 \%$ & - & - & - & $\mathrm{Z}_{1}$ & $30.4 \%$ & $7.6 \%$ \\
\hline 241 & $\mathrm{~B}_{1}$ & - & $8.7 \%$ & - & - & - & $\mathrm{B}_{1}$ & $21.3 \%$ & $23.2 \%$ & - & - & - \\
\hline 243 & - & - & - & $Y_{1}$ & $1.4 \%$ & - & - & - & - & $Y_{1}$ & $43.5 \%$ & $14.7 \%$ \\
\hline 259 & - & - & - & - & - & - & $\mathrm{C}_{1}$ & $13.5 \%$ & $2.27 \%$ & - & - & - \\
\hline 305 & - & - & - & - & - & - & - & - & - & $\mathrm{Z}_{3}$ & - & \\
\hline 313 & $\mathrm{~B}_{3}$ & $1.4 \%$ & $66.9 \%$ & - & - & - & $\mathrm{B}_{3}$ & - & $14.9 \%$ & - & - & - \\
\hline 314 & - & - & - & $Y_{3}$ & - & $57.1 \%$ & - & - & - & $Y_{3}$ & - & $27.2 \%$ \\
\hline 385 & $\mathrm{~B}_{2}$ & $53.3 \%$ & $69.6 \%$ & $\mathrm{~B}_{2}$ & $1.9 \%$ & $1.5 \%$ & $\mathrm{~B}_{2}$ & $63.2 \%$ & $16.7 \%$ & $\mathrm{~B}_{2}$ & $13.0 \%$ & $1.8 \%$ \\
\hline 403 & $\mathrm{Y}_{1}$ & $6.3 \%$ & $6.3 \%$ & $\mathrm{C}_{2}$ & $1.5 \%$ & $4.4 \%$ & $\mathrm{C}_{2}$ & $3.9 \%$ & $9.9 \%$ & $\mathrm{C}_{2}$ & $8.7 \%$ & $1.9 \%$ \\
\hline 405 & $Y_{2}$ & $87.2 \%$ & $100 \%$ & $Y_{2}$ & $2.5 \%$ & $8.6 \%$ & $Y_{2}$ & $100 \%$ & $20.8 \%$ & $\mathrm{Y}_{2}$ & $7.9 \%$ & $7.2 \%$ \\
\hline 547 & - & - & - & $\mathrm{B}_{3}$ & $24.6 \%$ & $2.5 \%$ & - & - & - & $\mathrm{B}_{3}$ & $9.0 \%$ & - \\
\hline 549 & $Y_{3}$ & $16.3 \%$ & $8.1 \%$ & $\mathrm{~B}_{3}$ & $9.3 \%$ & $11.8 \%$ & $Y_{3}$ & $2.6 \%$ & $2.2 \%$ & $\mathrm{~B}_{3}$ & $21.7 \%$ & $3.0 \%$ \\
\hline 565 & - & - & - & $\mathrm{C}_{3}$ & - & $2.9 \%$ & - & - & - & - & - & - \\
\hline 649 & - & - & - & $Y_{3}$ & $15.4 \%$ & - & - & - & - & - & - & - \\
\hline 650 & $\mathrm{~B}_{3}$ & $12.3 \%$ & - & $Y_{3}$ & - & $3 \%$ & - & - & - & $Y_{3}$ & $8.7 \%$ & \\
\hline 651 & - & - & - & $Y_{3}$ & $33.6 \%$ & - & - & - & - & - & - & - \\
\hline 693 & {$\left[\mathrm{M}-\mathrm{NaHSO}_{4}\right]^{-}$} & $29.0 \%$ & $2.3 \%$ & {$\left[\mathrm{M}-\mathrm{NaHSO}_{4}\right]^{-}$} & $100 \%$ & $14.0 \%$ & - & - & - & {$\left[\mathrm{M}-\mathrm{NaHSO}_{4}\right]^{-}$} & $8.8 \%$ & \\
\hline 733 & {$\left[\mathrm{M}-\mathrm{Na}-\mathrm{SO}_{3}\right]^{-}$} & $100 \%$ & - & {$\left[\mathrm{M}-\mathrm{Na}-\mathrm{SO}_{3}\right]^{-}$} & $61.1 \%$ & - & - & - & - & - & - & - \\
\hline
\end{tabular}

Collision energies were adjusted as shown in Figures 2, S4 and S5. 

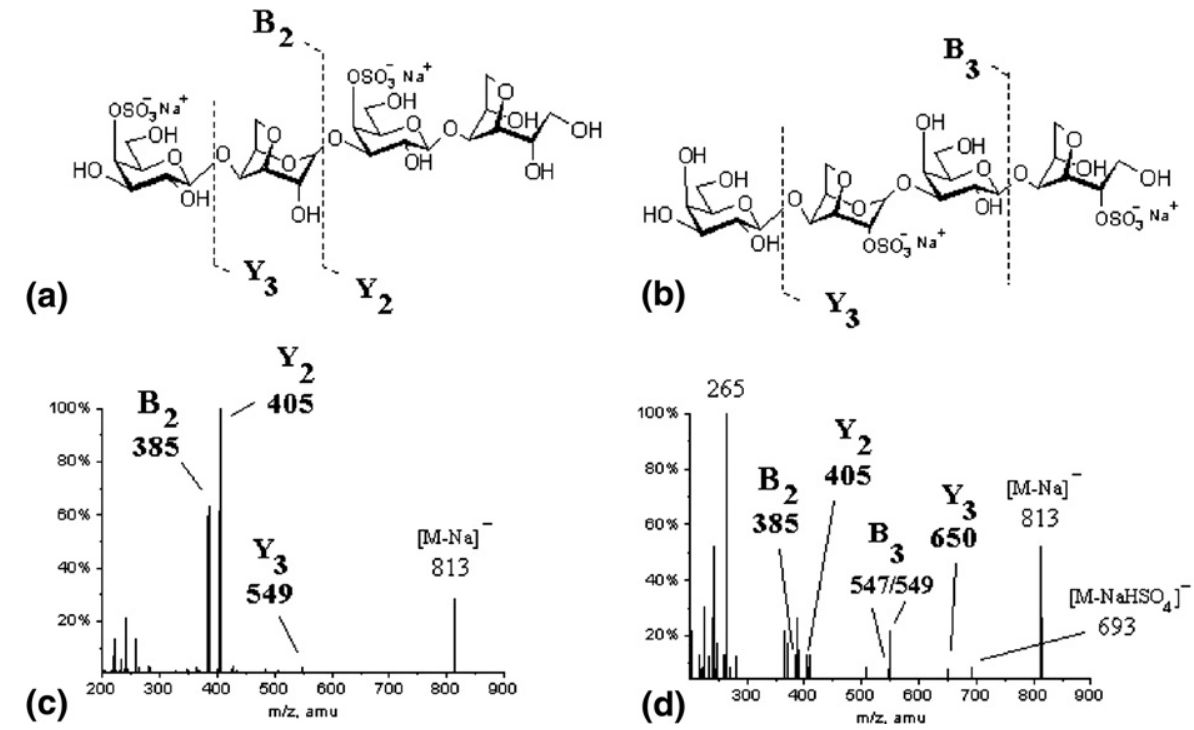

Figure 2. Characteristic glycosidic $[\mathrm{M}-\mathrm{Na}]^{-}$fragmentation patterns for G4S-A-G4S-AOH, 4(a) and G-A2S-G-AOH2S, 2(b). Negative-ion ESI CID MS/MS spectra at collision energy of $-70 \mathrm{eV}$ of G4S-A-G4S-AOH, 4(c) and G-A2S-G-AOH2S, 2(d) with [M-Na $]^{-}$at $m / z 813$ as precursor ion.

sponded to $7.9 \%$ and $13.0 \%$, respectively, with $\mathrm{m} / z 549$ $\left(\mathrm{B}_{3}\right)$ being the most abundant glycosidic fragment ion (21.7\%, Table 1). Also, G-A2S-G-AOH2S (2) [M-Na] ${ }^{-}$ CID MS/MS spectra presented two distinct $\mathrm{m} / \mathrm{z}$ values assigned to $\mathrm{B}_{3}(\mathrm{~m} / z 547$ and 549$)$ cleavages, which were explained by distinct stabilized fragment ions (from protonation and deprotonation of $\mathrm{B}_{3}$ ) that could be operating during glycosidic fragmentation. More importantly, this approach allowed facile differentiation between the isomers mainly because of the remarkable relative abundance differences (Table 1) for $B_{2}$ and $Y_{2}$ ions (compare spectra in Figure 2). Structures depicted in Figure $2 \mathrm{a}$ and $\mathrm{b}$ indicated the glycosidic $[\mathrm{M}-\mathrm{Na}]^{-}$ fragmentation patterns which were more characteristic for the tetrasaccharides, considering these two methodologies. These results also indicated that tetrasaccharide G4S-A-G4S-AOH (4) followed the same glycosidic fragmentation pattern observed for the kappa-carrageenan hexasaccharide: the main fragmentation event occurred at the glycosidic linkage closest to the sulfate group. For G-A2S-G-AOH2S (2) this effect was not observed. Previously published work [17] demonstrated that the sodium salts of sulfated carrageenan-derived oligosaccharides give a stable precursor ion [M-Na] ${ }^{-}$(presenting minor sulfate loss) which can be readily fragmented producing an extensive glycosidic bond cleavage (mainly C-, $\mathrm{Y}-$, and B-type cleavages). In the experiments described here, only B- and Y-ions were observed from glycosidic fragmentation, with $[\mathrm{M}-\mathrm{Na}]^{-}$as precursor, while Cand Z-ions were absent. Our findings are in accordance with a previously stated concept, which is consistent with the oxygen atom remaining with the reducing end species of glycosidic fragments [56].

Studies of the fragment ions from $[\mathrm{M}-2 \mathrm{Na}]^{2-}(\mathrm{m} / \mathrm{z}$ 395) presented additional fragment ions when compared to $[\mathrm{M}-\mathrm{Na}]^{-}$product ion spectra. Fragments from cleavages of all glycosidic bonds in the tetrasaccharide structures were observed, including C- and Z-type ions. As stated herein for singly charged product ion spectra, tetrasaccharide isomer differentiation could also be accomplished by evaluation of the $B_{2} / Y_{2}$ fragmentation pattern, which was the predominant fragmentation pathway for G4S-A-G4S-AOH (4), but not for G-A2SG-AOH2S (2) (Figure S4, Table 1). Quadrupole ion trap instrument gave $\mathrm{MS}^{2}$ spectra (Figure S5, Table 1), which were equivalents to the ESI CID MS/MS results, mainly in terms of the main glycosidic fragments.

\section{Product Ion Mass Spectra of Sulfated Disaccharide Alditols}

For the five monosulfated disaccharides G4S-AOH (3), G-AOH2S (1), G6S-AOH (7), G2S-AOH (6), and G3S$\mathrm{AOH}$ (8), single MS spectra of $[\mathrm{M}-\mathrm{Na}]^{-}$presented molecular ions at $\mathrm{m} / \mathrm{z} 405$ (Figure S6). As shown in Figure 3 , the four disaccharides containing the sulfate group on the galactopyranosidic unit presented CID MS/MS spectra with the $B_{1}$ ion at $m / z 241$ (as glycosidic fragment) and $\left[\mathrm{HSO}_{4}\right]^{-}$ion for all cases. Comparison of relative abundances of the $\left[\mathrm{HSO}_{4}\right]^{-}, \mathrm{B}_{1}$, and $[\mathrm{M}-\mathrm{Na}]^{-}$ ions (Figure 3, Table 2), under $-40 \mathrm{eV}$ collision energy demonstrated that compounds G4S-AOH (3) and G3SAOH (8) had higher abundances of [M-Na] ${ }^{-}(100 \%$ for both cases) while G6S-AOH (7) and G2S-AOH (6) underwent more facile glycosidic fragmentations, giving rise to relative abundances of $57.9 \%$ and $33.5 \%$ for molecular ion, respectively (Table 2). In accordance with these observations, $B_{1}$ relative intensities were consequently lower for G4S-AOH $(3,16.4 \%)$ and G3SAOH (8, 10.0\%) than for G6S-AOH (7, 36.7\%) and G2S-AOH (6, 100\%). We also observed that G2S-AOH 

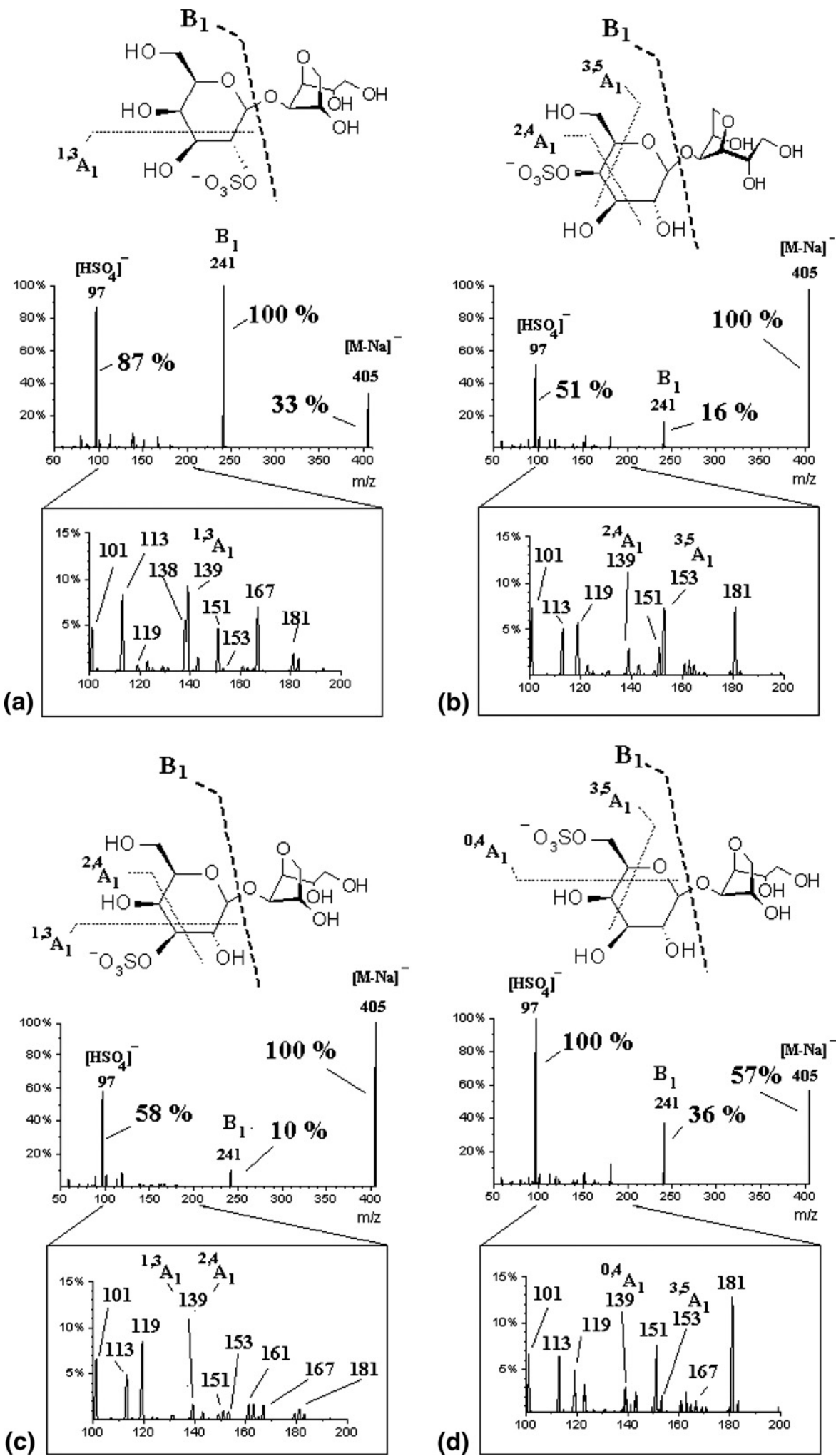

Figure 3. ESI CID MS/MS product ion spectra of G2S-AOH, 6 (a), G4S-AOH, 3 (b), G3S-AOH, 8 (c), and G6S-AOH, 7 (d) with [M-Na] ${ }^{-}$at $m / z 405$ as precursor ion. Spectral data recorded with a collision energy of $-40 \mathrm{eV}$. Relative abundances of $\left[\mathrm{HSO}_{4}\right]^{-}, \mathrm{B}_{1}$, and $[\mathrm{M}-\mathrm{Na}]^{-}$are indicated in the spectra. Inserts: expansion of the region from $\mathrm{m} / \mathrm{z} 100$ to 200 . 


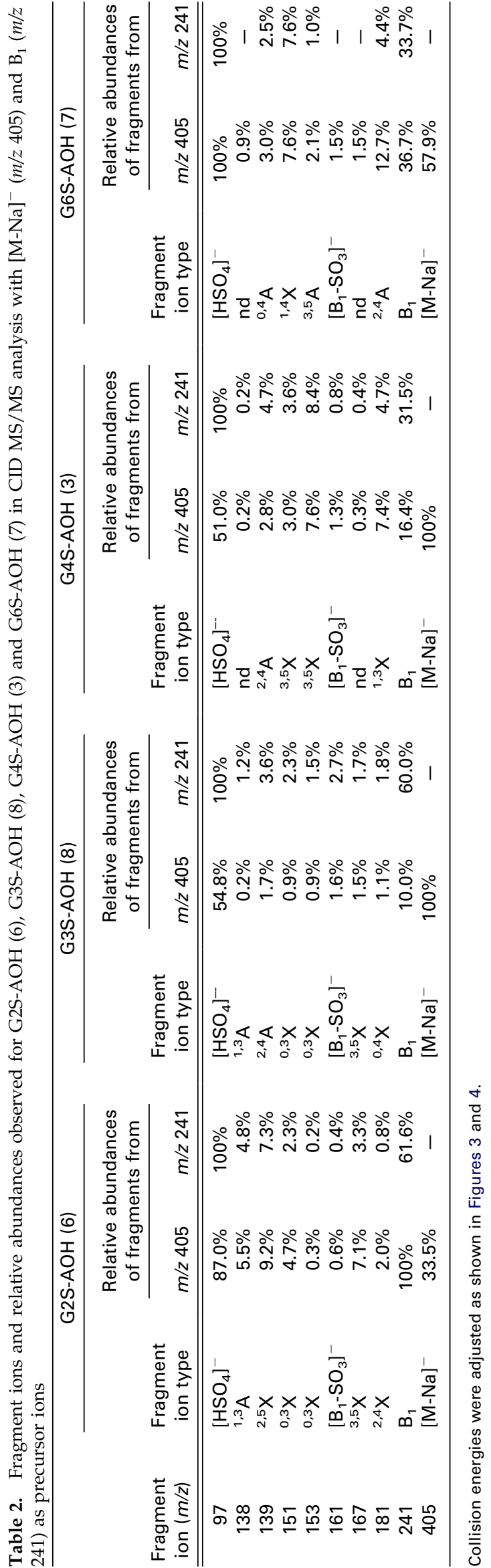

(6) and G6S-AOH (7) presented $\left[\mathrm{HSO}_{4}\right]^{-}$ions with higher relative intensities than did G4S-AOH (3) and G3S-AOH (8), which can also explain the lower relative abundance of $[\mathrm{M}-\mathrm{Na}]^{-}$for those oligosaccharides that had greater intensities for loss of sulfate (see Table 2). Despite this fact, the glycosidic cleavage observations are consistent with the previously proposed [20] sulfate-mediated hydrogen transfer for $B_{1}$ formation; we then concluded that this mechanism justifies the observation that the two oligosaccharides having the sulfate group spatially closer to the glycosidic linkage, G2S$\mathrm{AOH}$ (6) and G6S-AOH (7), undergo an easier $\mathrm{B}_{1}$ fragmentation. This supposition is also supported by glycosidic fragmentation patterns found for G4S-AG4S-AOH (4) and G4S-A-G4S-A-G4S-AOH (5). Interestingly, the opposite was only observed in the case of the tetrasaccharide G-A2S-G-AOH2S (2), which rendered minor ions resulting from $\mathrm{B}_{2} / \mathrm{Y}_{2}$ fragmentation. These statements indicate that the sulfate group attached to the carbon-2 of the 3,6-anhydrogalactosidic unit probably prevents the sulfate-mediated dissociation mechanism.

In the same spectra, the region from $\mathrm{m} / \mathrm{z} 100$ to $\mathrm{m} / \mathrm{z}$ 200 (inserts in Figure 4) presented several low relative abundance (less than $10 \%$ ) $\mathrm{m} / \mathrm{z}$ values, which appeared to be fragment ions from cross-ring cleavages. Some of these product ions could be readily assigned, such as $\mathrm{m} / \mathrm{z} 139$ and 153, however most of these fragments could not be related with any simple cross-ring dissociations. The relative abundance, and even the presence or absence of some of these fragments, were characteristic for each of the four isomer disaccharides (Table 2). We then concluded that their differentiation could be achieved by simple CID MS/MS product ion spectra having $[\mathrm{M}-\mathrm{Na}]^{-}$as precursor ion. Quadrupole ion trap gave similar results in terms $\mathrm{f}$ glycosidic fragmentation (Figure S7). However, cross-ring product ions were observed for G4S-AOH (3), G6S-AOH (7), G2S-AOH (6), and G3S-AOH (8) under the experimental conditions here employed.

The only distinctive product ion spectrum among those of the disaccharides in terms of glycosidic fragmentation was that of G-AOH2S (1) $[\mathrm{M}-\mathrm{Na}]^{-}$. The presence of the sulfate group on the 3,6-anhydrogalactosidic unit gave a protonated $Y_{1}$ ion at $\mathrm{m} / z$ 243. A fragment ion at $\mathrm{m} / \mathrm{z} 241$ was also present, which could be originated from deprotonation of $Y_{1}$. For G-AOH2S (1), MS $^{2}$ spectra also showed $\mathrm{m} / \mathrm{z} 285$, which was attributed to an ${ }^{0,2} \mathrm{X}_{1}$ cleavage in the non-sulfated Galp unit (Figure S8).

\section{Product Ion Mass Spectra from the $B_{1}$ Ion of Galactose-Sulfate Disaccharide Alditols}

To unambiguously differentiate the positional isomers G4S-AOH (3), G6S-AOH (7), G2S-AOH (6), and G3SAOH (8) via ESI-mass spectrometry, as well as to understand the origin of some of the fragment ions 

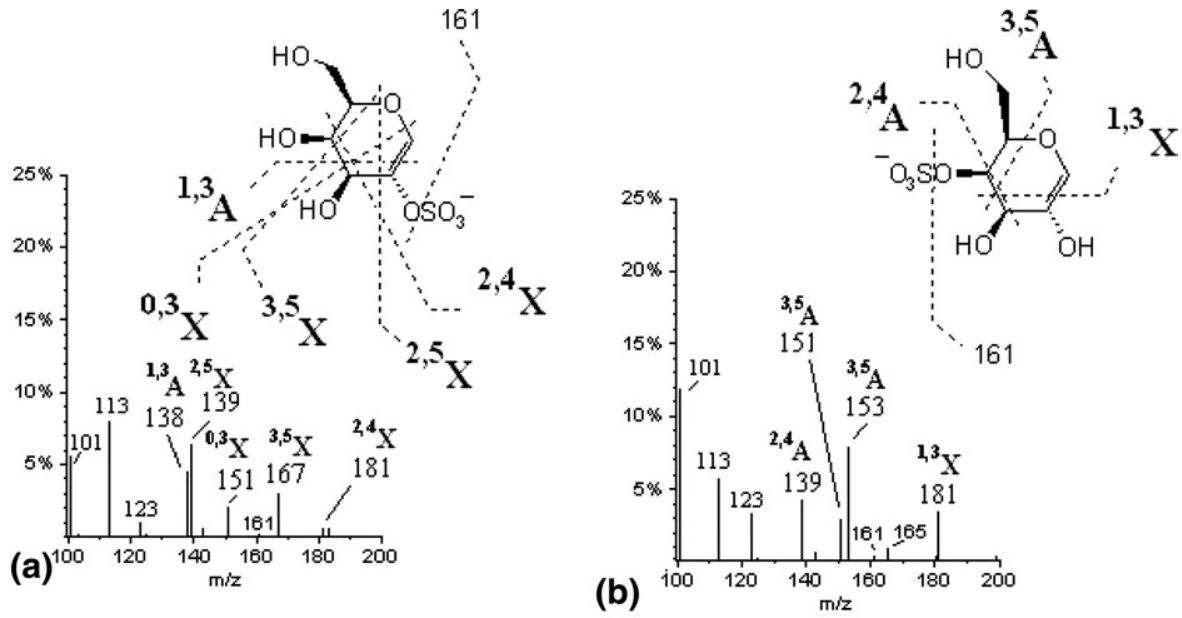

(c)
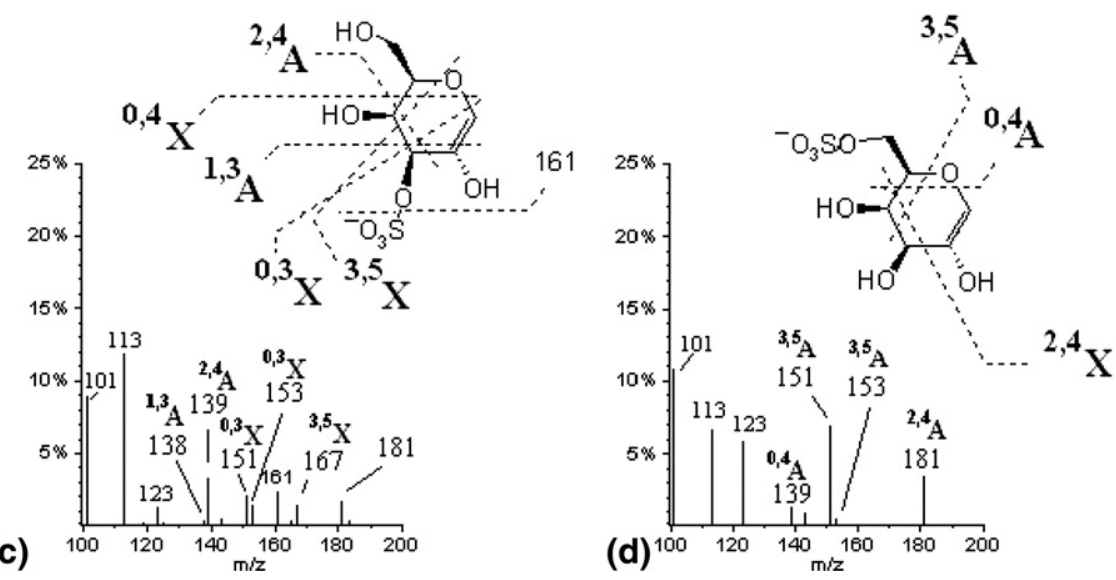

Figure 4. Expansions of $\mathrm{m} / \mathrm{z}$ 100-200 range of ESI CID MS/MS product ion centroid spectra of G2S-AOH, 6 (a), G4S-AOH, 3 (b), G3S-AOH, 8 (c) and G6S-AOH, 7 (d) with $\mathbf{B}_{1}$ at $\mathrm{m} / \mathrm{z} 241$ as precursor ion. Spectral data recorded with collision energy adjusted at $-30 \mathrm{eV}$.

observed in Figure 3, we performed CID MS/MS analysis on the $B_{1}$ ion $(m / z 241)$. For the triple quadrupole instrument, the best way to obtain this objective was to increase the IS and DP voltage values, which caused an increase in the in-source $B_{1}$ fragmentation. Product ion spectra from the precursor $B_{1}$ ion were then recorded with $-30 \mathrm{eV}$ of collision energy, keeping an abundant precursor ion with concomitant visualization of its daughter-ions. The success of this strategy was dependent of higher amounts of sample than those usually necessary to run ESI CID MS/MS experiments (see the Experimental section). The lack of sensitivity resulted mainly from a diminished amount of in-source produced $B_{1}$ ions in comparison to the unfragmented molecular ions. These experiments resulted in $\mathrm{m} / \mathrm{z} 97$ $\left[\mathrm{HSO}_{4}\right]^{-}$being the base peak in all cases (Figure S9, Table 2). The most informative $\mathrm{m} / \mathrm{z}$ range in these spectra was that from $\mathrm{m} / \mathrm{z} 100$ to 200 (Figure 4), which were very similar to the same range of the $[\mathrm{M}-\mathrm{Na}]^{-}$ product ion spectra (see inserts in Figure 3). To elucidate the origin of these fragment ions, we first attempted to establish the probable structure of the precursor $B_{1}$ ion. Along with glycosidic bond cleavage, previously general B-type cleavage mechanisms pro- pose: (a) epoxide formation [56]; (b) double bond formation (between C-1 and C-2) with ring opening [20], and (c) double bond formation without ring opening [56]. The $B_{1}$ formation mechanism that better explains most of our results corresponds to (c) as shown in Scheme 1 [56].

Most of the $B_{1}$ product ion fragments were observed for the four isomers studied here, such as, the $\mathrm{m} / \mathrm{z} 101$, 113, 123, 139, 151, and 181 ions. The isomers could be differentiated effectively by comparative observation of the peaks at $m / z 138,139,151,153$, and 167. Fragment ions at $\mathrm{m} / \mathrm{z} 138$ and 167 were only found in considerable relative abundances for G2S-AOH (6) and G3S-AOH (8) (Figure 4, Table 2); the formation of these ions could be explained through ${ }^{1,3} \mathrm{~A}$ and ${ }^{3,5} \mathrm{X}$ fragmentations, respectively, for both cases. According to our cross-ring fragmentation mechanisms, those two $\mathrm{m} / \mathrm{z}$ values could not be generated from G4S-AOH (3) and G6S-AOH (7). Comparative analysis of the relative abundances for $\mathrm{m} / \mathrm{z}$ 138 ions also gave us important data for G2S-AOH (6)/G3S-AOH (8) differentiation, with the $\mathrm{m} / z 138$ peak being much more abundant for the 2-sulfated isomer $(4.8 \%)$, while this fragment ion was four times less abundant for the 3 -sulfated species $(1.2 \%)$, as shown in 


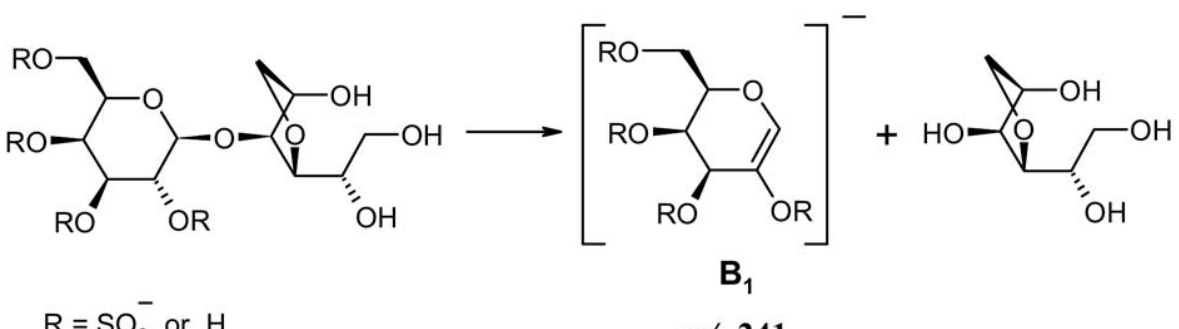

$\mathrm{R}=\mathrm{SO}_{3}^{-}$or $\mathrm{H}$

$m / z, 241$

Scheme 1. Dissociation mechanism for formation of $B_{1}$ ions for G2S-AOH (6), G4S-AOH (3), G3S-AOH (8). and G6S-AOH (7).

Table 2. Formation of the $m / z 139$ ion, which was present in the spectra of the four galactose-sulfate isomers, could be readily explained for G3S-AOH (8) $\left({ }^{2,4} \mathrm{~A}\right)$, G4S-AOH $(3)\left({ }^{2,4} \mathrm{~A}\right)$, and G6S-AOH $(7)\left({ }^{0,4} \mathrm{~A}\right)$, as demonstrated in Figure 4 b, $c$, and d. However we could not propose a simple fragmentation mechanism that gives $m / z 139$ from a cyclic 2 -sulfated $B_{1}$ ion. In this case, we based our explanation on the mechanism previously described [20] for $\mathrm{B}_{1}$ formation from a 2-O-SO $\mathrm{S}_{3}$-heparin disaccharide, which included a ring-opening step. The sulfate group, located adjacent to the glycosidic linkage, abstracts the O-3 proton to generate an O-3 anion, which leads to elimination of the glycosyloxy group (Scheme S2a); CID on $\mathrm{B}_{1}$ leads then to $\mathrm{C} 5-\mathrm{O} 5$ bond cleavage to give a stable $m / z 139$ ion [28] (Scheme S2b).

As shown in Figure $4 a$, we also could observe some fragment ions from the cyclic $B_{1}$ pathway for $\mathrm{G} 2 \mathrm{~S}-\mathrm{AOH}$ (6), so we assumed that both types of $B_{1}$ ions could be generated in this case. This is supported by the high $\mathrm{B}_{1}$ relative abundance (100\%) observed for G2S-AOH (6) in $[\mathrm{M}-\mathrm{Na}]^{-}$product ion spectrum (Table 2, Figure 3a), which could be originating from the two possible cleavage mechanisms. The intensities of fragment ions at $m / z 153$ were also considered to be key to differentiation between G2S-AOH (6) and G3S-AOH (8), since this peak had a very low intensity $(0.2 \%)$ in the spectrum of the 2-sulfated compound. Comparative analysis of the relative abundance for the $m / z 151$ and 153 ions gave us important data for G4S-AOH (3)/G6S-AOH (7) differentiation, with the $\mathrm{m} / \mathrm{z} 153$ ion being more abundant $(8.4 \%)$ than the $m / z 151$ ion $(3.6 \%)$ in the case of the 4-sulfated $B_{1}$ ion, while the opposite was characteristic of the spectra of the 6-sulfated compound (Table 2 ). The mechanisms for formation of the $m / z 151$ and 153 ions are thought to be an ${ }^{0,3} \mathrm{X}$ cleavage for G2S-AOH (6) and G3S-AOH (8), and an ${ }^{3,5} \mathrm{X}$ for G4S-AOH (3) and G6S-AOH (7) The predominance of the $m / z 151$ peak in the G2S-AOH (6) spectrum, as well as the presence of an $m / z 153$ peak for G3S-AOH (8) was understood as depicted in Scheme S3; the position occupied by the sulfate group induced the differential stabilization of these two isomeric species. Comparison of these hypotheses to those proposed for G4S-AOH (3) and G6S-AOH (7) indicated that when the bond involved in the cleavage process links a sulfated carbon, the predominant product ion is the $m / z 153$ ion; otherwise, the sulfated fragment tend to stabilize ions with $\mathrm{m} / \mathrm{z}$ of 151 .
For both $[\mathrm{M}-\mathrm{Na}]^{-}$and $\mathrm{B}_{1}$ product ion spectra, the region of the spectra from $m / z 100$ to 200 were notably similar (compare inserts in Figure 3 to spectra in Figure $4)$. Due to the presence of the same X-type ions in these spectra, we propose that during $[\mathrm{M}-\mathrm{Na}]^{-} \mathrm{CID}$, a $\mathrm{B}_{1}$ "expulsion" [30] accompanied by the simultaneous generation of its product ions has occurred. By employing $[\mathrm{M}-\mathrm{Na}]^{-}$or $\mathrm{B}_{1}$ product ion spectra, and evaluating the relative abundances for $m / z 138,139,151$, and 153 allowed us to differentiate the galactose-sulfate isomers disaccharides effectively (Figure 5).

As we were examining fragments of a fragment in this study, we introduced $\mathrm{MS}^{3}$ analysis by use of the ESI-quadrupole ion trap instrument attempting to obtain results similar to those obtained in $\mathrm{m} / \mathrm{z} 241 \mathrm{~B}_{1}$ ESI-CID MS/MS fragmentation. Surprisingly, $\mathrm{MS}^{3}$ spectra (Figure S10) were less informative than those obtained by the triple quadrupole analysis. Some fragments were present for both techniques, such as ions at $m / z$ 97, 110, 113, and 181. However, most ions found in this analysis could not be assigned using the mechanisms presented in Figure 4, indicating that different dissociative mechanisms are probably operating when this technique is used, at least for the types of compounds studied here.

\section{Conclusions}

We have prepared a set of sulfated red seaweed galactanderived oligosaccharide that includes all possible galactosyl-sulfated isomers of the galactopyranosyl alditol disaccharides plus a number of larger oligosaccharides. Isomeric series were evaluated by use of two different ESI-mass spectrometric techniques: ESI CID MS/MS and ESI MS ${ }^{n}$. Product ion spectra of G4S-AG4S-A-G4S-AOH (5), G4S-A-G4S-AOH (4) and GA2S-G-AOH2S (2) indicated that the location of the sulfate groups, which are close to glycosidic bonds, can induce or inhibit glycosidic cleavages. These effects depended of the type of monosaccharide unit and the specific sulfate attachment position. Both techniques gave equivalent results for hexa- and tetrasaccharides analysis, which allowed the differentiation of the two isomeric tetrasaccharides. We also demonstrated the CID MS/MS differentiation of the four isomeric sulfated disaccharides, which presented all monosulfation possibilities on the Gal $p$ ring G4S-AOH (3), G6S-AOH 


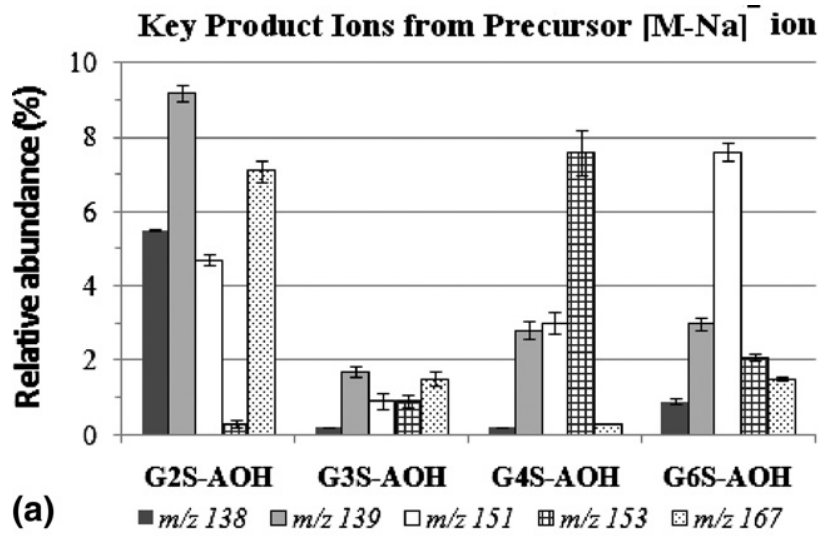

Key Product Ions from Precursor $B_{1}$ ion

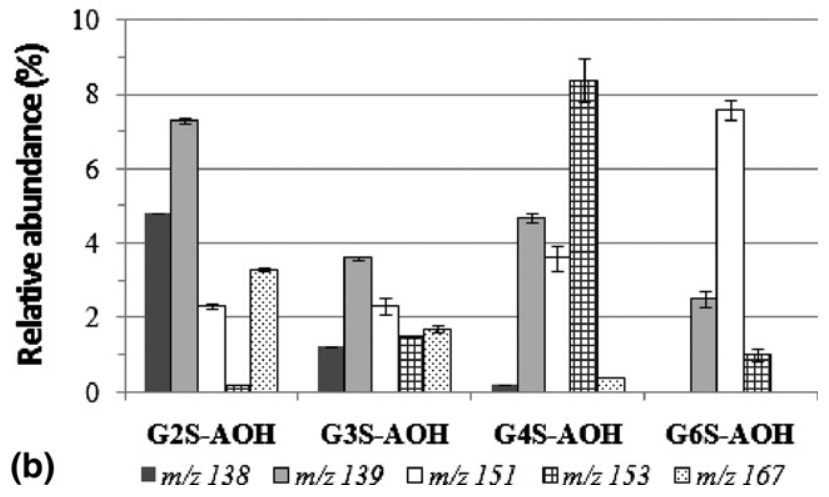

Figure 5. Relative abundances for product ions at $m / z$ 138, 139, 151, 153, and 167 of G2S-AOH (6), G3S-AOH (8), G4S-AOH (3), and G6S-AOH (7) with [M-Na] ${ }^{-}(\mathbf{a})$ and $\mathrm{B}_{1}(\mathbf{b})$ as precursor ions. Mass spectrometric conditions were as in Figures 3 and 4, respectively. Error bars were determined with distinct acquisitions $(n=3)$.

(7), G2S-AOH (6), and G3S-AOH (8) isomeric disaccharide differentiation were achieved by the use of two strategies: CID MS/MS for [M-Na] $]^{-}$and for $\mathrm{B}_{1}$ ion. The second approach was performed through the increasing of the in-source fragmentation, generating abundant $\mathrm{B}_{1}$ precursor ions for subsequent CID. Based on these results, we propose explanations for product ion formations. In addition, differences arising from the differences between the two mass spectrometric techniques are identified. The methods used for spectral data analysis presented here are not only useful for red seaweed galactan-derivative oligosaccharide analysis but also should be applicable to the analysis of data from other types of sulfated oligosaccharides.

\section{Acknowledgments}

TBG thanks NSERC for support. The authors thank PRONEXCARBOIDRATOS and CNPq for financial support.

\section{Appendix A Supplementary Material}

Supplementary material associated with this article may be found in the online version at doi:10.1016/j. jasms.2010.03.045.

\section{References}

1. Laabs, T.; Carulli, D.; Geller, H. M.; Fawcett, J. W. Chondroitin Sulfate Proteoglycans in Neural Development and Regeneration. Curr. Opin. Neurobiol. 2005, 15, 116-120.

2. Sasisekharan, R.; Shriver, Z.; Venkataraman, G.; Narayanasami, U. Roles of Heparan-Sulphate Glycosaminoglycans in Cancer. Nat. Rev. Cancer. 2002, 2, 521-528.

3. Yip, G. W.; Smollich, M.; Gotte, M. Therapeutic Value of Glycosaminoglycans in Cancer. Mol. Cancer Ther. 2006, 5, 2139-2148.

4. Capila, I.; Linhardt, R. J. Heparin-Protein Interactions. Angeww. Chem. Int. Ed. 2002, 41, 391-412.

5. Kisilevsky, R.; Ancsin, J. B.; Szarek, W. A.; Petanceska, S. Heparan Sulfate as a Therapeutic Target in Amyloidogenesis: Prospects and Possible Complications. Amyloid 2007, 14, 21-32.

6. Gama, C. I.; Hsieh-Wilson, L. C. Chemical Approaches to Deciphering the Glycosaminoglycan Code. Curr. Opin. Chem. Biol. 2005, 9, 609-619.

7. Gama, C. I.; Tully, S. E.; Sotogaku, N.; Clark, P. M.; Rawat, M.; Vaidehi, N.; Goddard, W. A. III; Nishi, A.; Hsieh-Wilson, L. C. Sulfation Patterns of Glycosaminoglycans Encode Molecular Recognition and Activity. Nat. Chem. Biol. 2006, 2, 467-473.

8. Thomsson, K. A.; Karlsson, N. G.; Hansson, G. C. Liquid Chromatographyelectrospray Mass Spectrometry as a Tool for the Analysis of Sulfated Oligosaccharides from Mucin Glycoproteins. J. Chromatogr. A 1999, 854, 131-139.

9. Thomsson, K. A.; Karlsson, H.; Hansson, G. C. Sequencing of Sulfated Oligosaccharides from Mucins by Liquid Chromatography and Electrospray Ionization Tandem Mass Spectrometry. Anal. Chem. 2000, 72, 4543-4549.

10. Ekeberg, D.; Knutsen, S. H.; Sletmoen, M. Negative-Ion Electrospray Ionization-mass Spectrometry (ESI-MS) as a Tool for Analyzing Structural Heterogeneity in $\kappa$-carrageenan Oligosaccharides. Carbohydr. Res. 2001, 334, 49-59.

11. Zaia, J.; Costello, C. E. Compositional Analysis of Glycosaminoglycans by Electrospray Mass Spectrometry. Anal. Chem. 2001, 73, 233-239.

12. Zaia, J.; Costello, C. E. Tandem Mass Spectrometry of Sulfated HeparinLike Glycosaminoglycan Oligosaccharides. Anal. Chem. 2003, 75, 2445 2455.

13. Lamb, D. J.; Wang, H. M.; Mallis, L. M.; Linhardt, R. J. Negative Ion Fast-Atom Bombardment Tandem Mass Spectrometry to Determine Sulfate and Linkage Position in Glycosaminoglycan-derived Disaccharides. J. Am. Soc. Mass Spectrom. 1992, 3, 797-803.

14. Linhardt, R. J.; Wang, H. M.; Loganathan, D.; Lamb, D. J.; Mallis, L. M. Analysis of Glycosaminoglycan-derived Oligosaccharides Using FastAtom-Bombardment Mass-Spectrometry. Carbohydr. Res. 1992, 225, 137 145.

15. Fukuyama, Y.; Ciancia, M.; Nonami, H.; Cerezo, A. S.; Erra-Balsells, R.; Matulewicz, M. C. Matrix-Assisted Ultraviolet Laser-Desorption Ionization and Electrospray-Ionization Time-of-Flight Mass Spectrometry of Sulfated Neocarrabiose Oligosaccharides. Carbohydr. Res. 2002, 337, 1553-1562.

16. Laremore, T. N.; Zhang, F.; Linhardt, R. J. Ionic Liquid Matrix for Direct UV-MALDI-TOF-MS Analysis of Dermatan Sulfate and Chondroitin Sulfate Oligosaccharides. Anal. Chem. 2007, 79, 1604-1610.

17. Yu, G.; Zhao, X.; Yang, B.; Ren, S.; Guan, H.; Zhang, Y.; Lawson, A. M.; Chai, W. Sequence Determination of Sulfated Carrageenan-Derived Oligosaccharides by High-Sensitivity Negative-ion Electrospray Tandem Mass Spectrometry. Anal. Chem. 2006, 78, 8499-8505.

18. Gunay, N. S.; Tadano-Aritomi, K.; Toida, T.; Ishizuka, I.; Linhart, R. J Evaluation of Counterions for Electrospray Ionization Mass Spectral Analysis of a Highly Sulfated Carbohydrate, Sucrose Octasulfate. Anal. Chem. 2003, 75, 3226-3231.

19. Saad, O. M.; Leary, J. A. Compositional Analysis and Quantification of Heparin and Heparan Sulfate by Electrospray Ionization Ion Trap Mass Spectrometry. Anal. Chem. 2003, 75, 2985-2995.

20. Saad, O. M.; Leary, J. A. Delineating Mechanisms of Dissociation for Isomeric Heparin Disaccharides Using Isotope Labeling and Ion Trap Tandem Mass Spectrometry. J. Am. Soc. Mass Spectrom. 2004, 15, 1274-1286.

21. Yu, G.; Guan, H.; Ioanoviciu, A. S.; Sikkander, S. A.; Thanawiroon, C.; Tobacman, J. K.; Toida, T.; Linhardt, R. J. Structural Studies on $\kappa$ Carrageenan Derived Oligosaccharides. Carbohydr. Res. 2002, 337, 433-440.

22. Korir, A. K.; Limtiaco, J. F.; Gutierrez, S. M.; Larive, C. K. Ultraperformance Ion-Pair Liquid Chromatography Coupled to Electrospray Timeof-Flight Mass Spectrometry for Compositional Profiling and Quantification of Heparin and Heparan Sulfate. Anal. Chem. 2008, 80, 1297-1306.

23. Meissen, J. K.; Sweeney, M. D.; Girardi, M.; Lawrence, R.; Esko, J. D.; Leary, J. A. Differentiation of 3-O-Sulfatated Heparin Disaccharide Isomers: Identification of Structural Aspects of the Heparin CCL2 Binding Motif. J. Am. Soc. Mass Spectrom. 2009, 20, 652-657.

24. Mason, K. E.; Meikle, P. J.; Hopwood, J. J.; Fuller, M. Characterization of Sulfated Oligosaccharides in Mucopolysaccharidosis Type IIIA by Electrospray Ionization Mass Spectrometry. Anal. Chem. 2006, 78, 45344542 .

25. Zaia, J.; McClellan, J. E.; Costello, C. E. Tandem Mass Spectrometric Determination of the 4S/6S Sulfation Sequence in Chondroitin Sulfate Oligosaccharides. Anal. Chem. 2001, 73, 6030-6039.

26. McClellan, J. M.; Costello, C. E.; O'Connor, P. B.; Zaia, J. Influence of Charge State on Product Ion Mass Spectra and the Determination of 
4S/6S Sulfation Sequence of Chondroitin Sulfate Oligosaccharides. Anal. Chem. 2002, 74, 3760-3771.

27. Zaia, J.; Li, X. Q.; Chan, S. Y.; Costello, C. E. Tandem Mass Spectrometric Strategies for Determination of Sulfation Positions and Uronic Acid Epimerization in Chondroitin Sulfate Oligosaccharides. J. Am. Soc. Mass Spectrom. 2003, 14, 1270-1281.

28. Tissot, B.; Salpin, J.-Y.; Martinez, M.; Gaigeot, M.-P.; Daniel, R. Differentiation of the Fucoidan Sulfated L-Fucose Isomers Constituents by CE-ESIMS and Molecular Modeling. Carbohydr. Res. 2006, 341, 598-609.

29. Ii, T.; Okuda, S.; Hirano, T.; Ohashi, M. Tandem Mass Spectrometry for Characterization of Unsaturated Disaccharides from Chondroitin Sulfate, Dermatan Sulfate, and Hyaluronan. Glycoconj. I. 1994, 11, 123-132.

30. Liu, R. H.; Chanthamontri, C.; Han, H. L.; Han, H.; Hernández-Torres, J. M.; Wood, K. V.; McLuckey S. A.; Wei, A. Solid-Phase Synthesis of $\alpha$-Glucosamine Sulfoforms with Fragmentation Analysis by Tandem Mass Spectrometry. J. Org. Chem. 2008, 73, 6059-6072.

31. Gonçalves, A. G.; Ducatti, D. R. B.; Duarte, M. E. R.; Noseda, M. D. Sulfated and Pyruvylated Disaccharide Alditols Obtained from a Red Seaweed Galactan: ESIMS and NMR Approaches. Carbohydr. Res. 2002, 337, 2443-2453.

32. Antonopoulos, A.; Favetta, P.; Helbert, W.; Lafosse, M. Isolation of $\kappa-$ Carrageenan Oligosaccharides Using Ion-Pair Liquid ChromatographyCharacterization by Electrospray Ionization Mass Spectrometry in Positive-Ion Mode. Carbohydr. Res. 2004, 339, 1301-1309.

33. Antonopoulos, A.; Favetta, P.; Helbert, W.; Lafosse, M. On-Line Liquid Chromatography Electrospray Ionization Mass Spectrometry for the Characterization of $\kappa$ - and $\iota$-Carrageenans. Application to the Hybrid $\iota / \nu$-Carrageenans. Anal. Chem. 2005, 77, 4125-4136.

34. Gonçalves, A. G.; Ducatti, D. R. B.; Paranha, R. G.; Duarte, M. E. R.; Noseda, M. D. Positional Isomers of Sulfated Oligosaccharides Obtained from Agarans and Carrageenans: Preparation and Capillary Electrophoresis Separation. Carbohydr. Res. 2005, 340, 2123-2134.

35. Aguilan, J. T.; Dayrit, F. M.; Zhang, J.; Niñonuevo, M. R.; Lebrilla, C. B. Structural Analysis of $\kappa$-Carrageenan Sulfated Oligosaccharides by Positive Mode Nano-ESI-FTICR-MS and MS/MS by SORI-CID. J. Am. Soc. Mass Spectrom. 2006, 17, 96-103.

36. Antonopoulos, A.; Favetta, P.; Helbert, W.; Lafosse, M. On-Line Liquid Chromatography-electrospray Ionisation Mass Spectrometry for $\kappa$ Carrageenan Oligosaccharides with a Porous Graphitic Carbon Column. J. Chromatogr. A 2007, 1147, 37-41.

37. Yang B.; Yu G. L.; Zhao X.; Jiao G. L.; Ren S. M.; Chai, W. G. Mechanism of Mild Acid Hydrolysis of Galactan Polysaccharides with Highly Ordered Disaccharide Repeats Leading to a Complete Series of Exclusively Odd-Numbered Oligosaccharides. FEBS J. 2009, 276, 2125-2137.

38. Painter, T. J. Algal Polysaccharides. In The Polysaccharides, Aspinall, G. O., Ed.; Academic Press: New York, 1983; p. 195.

39. De Ruiter, G. A.; Rudolph, B. Carrageenan Biotechnology. Trends Food. Sci. Technol. 1997, 8, 389-95.

40. Usov, A. I. Structural Analysis of Red Seaweed Galactans of Agar and Carrageenan Groups. Food Hydrocoll. 1998, 12, 301-308

41. Ciancia, M.; Noseda, M. D.; Matulewicz, M. C.; Cerezo, A. S. AlkaliModification of Carrageenans: Mechanism and Kinetics in the $\kappa / \iota-\mu / \nu-$, and $\lambda$-series. Carbohydr. Polym. 1993, 20, 95-98.

42. Noseda, M. D.; Cerezo, A. S. Alkali Modification of Carrageenans. II. The Cyclization of Model Compounds Containing Nonsulfated $\beta$-DGalactose Units. Carbohydr. Polym. 1995, 26, 1-3.

43. Noseda M. D.; Viana, A. G.; Duarte, M. E. R.; Cerezo A. S. Alkali Modification of Carrageenans. Part I. V. Porphyrans as Model Compounds. Carbohydr. Polym. 2000, 42, 301-305.

44. Viana A. G.; Noseda, M. D.; Duarte M. E. R.; Cerezo, A. S. Alkali Modifications of Carrageenans. Part V. The $\iota-1$ Hybrid Carrageenan from Eucheuma denticulatum and its Cyclization to ı-Carrageenan. Carbohydr. Polym. 2004, 58, 455-460.

45. Zibetti R. G. M.; Noseda, M. D.; Cerezo, A. S.; Duarte, M. E. R. The System of Galactans from Cryptonemia crenulata (Halymeniaceae, Halymeniales) and the Structure of Two Major Fractions. Kinetic Studies on the Alkaline Cyclization of the Unusual Diad G2S $\rightarrow$ D(L)6S. Carbohydr. Res. 2005, 340, 711-722.
46. Carlucci, M. J.; Pujol, C. A.; Ciancia, M.; Noseda, M. D.; Matulewicz, M. C.; Damonte, E. B.; Cerezo, A. S. Antiherpetic and Anticoagulant Properties of Carrageenans from the Red Seaweed Gigartina skottsbergi and their Cyclized Derivatives: Correlation Between Structure and Biological Activity. Int. J. Biol. Macromol. 1997, 20, 97-105.

47. Duarte, M. E. R.; Noseda, D. G.; Noseda, M. D.; Tulio, S.; Pujol, C. A. Damonte, E. B. Inhibitory Effect of Sulfated Galactans from the Marine Alga Bostrychia montagnei on Herpes Simplex Virus Replication In Vitro. Phytomedicine 2001, 8, 53-58.

48. Duarte, M. E. R.; Cauduro, J. P.; Noseda, D. G.; Noseda, M. D. Gonçalves, A. G.; Pujol, C. A.; Damonte, E. B.; Cerezo, A. S. The Structure of the Agaran Sulfate from Acanthophora spicifera (Rhodomelaceae, Ceramiales) and Its Antiviral Activity. Relation Between Structure and Antiviral Activity in Agarans. Carbohydr. Res. 2004, 339, 335-347.

49. Talarico, L. B.; Zibetti, R. G. M.; Faria, P. C. S.; Scolaro, L. A.; Duarte, M. E. R.; Noseda, M. D.; Pujol, C. A.; Damonte, E. B. Anti-Herpes Simplex Virus Activity of Sulfated Galactans from the Red Seaweeds Gymnogongrus griffithsiae and Cryptonemia crenulata. Int. J. Biol. Macromol. 2004, 34, 63-71.

50. Harden, E. A.; Falshaw, R.; Carnachan, S. M.; Kern, E. R.; Prichard M. N. Virucidal Activity of Polysaccharide Extracts from Four Algal Species Against Herpes Simplex Virus. Antivir. Res. 2009, 83, 282-289.

51. Talarico, L. B.; Damonte, E. B. Interference in Dengue Virus Adsorption and Uncoating by Carrageenans. Virology 2007, 363, 473-485.

52. Talarico, L. B.; Pujol, C. A.; Zibetti, R. G. M.; Faria, P. C. S.; Noseda, M. D.; Duarte, M. E. R.; Damonte, E. B. The Antiviral Activity of Sulfated Polysaccharides Against Dengue Virus is Dependent on Virus Serotype and Host Cell. Antivir. Res. 2005, 66, 103-110.

53. De S. F.-Tisher, P. C.; Talarico, L. B.; Noseda, M. D.; Guimarães, S. M. P. B.; Damonte, E. B.; Duarte, M. E. R. Chemical Structure and Antiviral Activity of Carrageenans from Meristiella gelidium Against Herpes Simplex and Dengue Virus. Carbohydr. Polym. 2006, 63, 459-465.

54. Ghosh, T.; Chattopadhyay, K.; Marschall, M.; Karmakar, P.; Mandal, P.; Ray, B. Focus on Antivirally Active Sulfated Polysaccharides: From Structure-activity Analysis to Clinical Evaluation. Glycobiology 2009, 19, 2-15.

55. Gonçalves, A. G.; Noseda, M. D.; Duarte, M. E. R.; Grindley, T. B. Semi-synthesis of a 3-O-sulfated Red Seaweed Galactan-Derived Disaccharide Alditol. Carbohydr. Res. 2006, 341, 1753-1757.

56. Domon, B.; Costello, C. E. A Systematic Nomenclature for Carbohydrate Fragmentations in FAB-MS/MS Spectra of Glycoconjugates. Glycoconj. J. 1988, 5, 397-409.

57. Matulewicz M. C.; Ciancia M.; Noseda, M. D.; Cerezo, A. S. Methylation Analysis of Carrageenans from Tetrasporic and Cystocarpic Stages of Gigartina skottsbergii. Phytochemistry 1990, 29, 3407-3410.

58. Guimarães, M.; Viana, A. G.; Duarte, M. E. R.; Ascêncio, S. D.; Plastino, E. M.; Noseda, M. D. Low-Molecular-Mass Carbohydrates and Soluble Polysaccharides of Green and Red Morphs of Gracilaria domingensis (Gracilariales, Rhodophyta). Bot. Mar. 2007, 50, 314.

59. Usov, A. I.; Elashvili, M. Polysaccharides of Algae 44. Investigation of Sulfated Galactan from Laurencia nipponica Yamada (Rhodophyta, Rhodomelaceae), Using Partial Reductive Hydrolysis. Bot. Mar. 1991, 34, 553-560.

60. Gonçalves, A. G.; Noseda, M. D.; Duarte, M. E. R.; Grindley, T. B. Semi-Synthesis of Long Chain Alkyl Ether Derivatives of Sulfated Oligosaccharides Via Dibutylstannylene Acetal Intermediates. J. Org. Chem. 2007, 72, 9896-9904.

61. Falshaw, R.; Furneaux, R. H. The Structural Analysis of Disaccharides from Red Algal Galactans by Methylation and Reductive Partialhydrolysis. Carbohydr. Res. 1995, 269, 183-189.

62. Usov, A. I.; Elashvili, M. Polysaccharides from Algae. 51. Partial Reductive Hydrolysis of Sulfated Galactan from Red Alga Laurencia coronopus J. Ag. (Rhodophyta, Rhodomelaceae). Russ. J. Bioorg. Chem. 1997, 23, 468-173.

63. Falshaw, R.; Furneaux, R. H.; Wong, H. Analysis of Pyruvylated $\beta$-Carrageenan by 2D NMR Spectroscopy and Reductive partial Hydrolysis. Carbohydr. Res. 2003, 338, 1403-1414. 